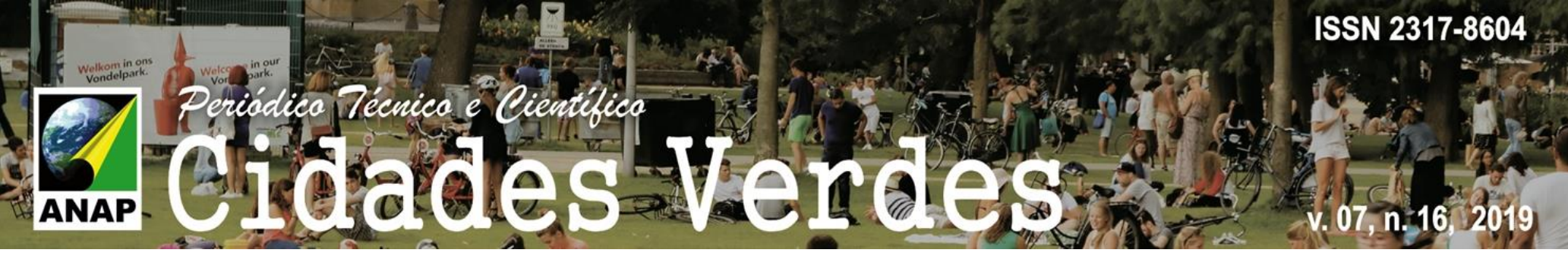

\title{
Produção, consumo e destinação de resíduos: a percepção dos discentes do curso de gestão ambiental da uern sobre sacolas plásticas
}
Waste production, consumption and disposal: the perception of students from the uern environmental management course on plastic bags

Producción, consumo y eliminación de residuos: la percepción de estudiantes del curso de gestión ambiental uern en bolsas de plástico

Márcia Regina Farias da Silva Professora Adjunta IV do Departamento de Gestão Ambiental, FACEM - UERN mreginafarias@hotmail.com

\section{Larissa Fernandes da Silva}

Mestranda em Manejo de Solo e Água, Universidade Federal Rural do Semiárido - UFERSA, Brasil larissafs.ga@gmail.com

Enaira Liany Bezerra dos Santos Graduanda em Gestão Ambiental, Universidade do Estado do Rio Grande do Norte - UERN, Brasil enairasantos@alu.uern.br 


\section{INTRODUÇÃO}

O termo plástico advém do grego "plastikos" e significa "próprio para ser moldado" (ALVES; ARAÚJO, 2018). O consumo exagerado de plástico e a falta de destinação adequada desses tem desencadeado uma série de impactos no meio ambiente e na saúde humana.

A produção de plásticos convencionais causa impactos à atmosfera, ao solo, a água e a outros componentes do meio físico por ter como matéria-prima subprodutos do petróleo (SILVA; RABELO, 2017). O seu consumo exagerado aumenta a probabilidade desse estar sendo descartado inadequadamente. Estudos como o de Mizoguchi (2019) mostra como o descarte inadequado de artefatos plásticos gera graves danos à fauna marinha, à saúde humana e ao ambiente físico, a partir da liberação de petropolímeros. Cerca de $10 \%$ do resíduo total gerado no Brasil é formado por sacolas plásticas (LOZENZETT, 2013), um dos artefatos plásticos presentes em toda e qualquer compra.

Torna-se imperativo a busca pela resolução do problema, e dada à necessidade da adoção de práticas de "Produção e Consumo Sustentáveis", foi dedicado um Objetivo de Desenvolvimento Sustentável na Agenda 2030 para o Desenvolvimento Sustentável a esta temática. No seu ODS 12, de Produção e Consumo Sustentáveis, é salientada a necessidade de se atentar à diminuição de geração de resíduos, ao melhor gerenciamento desses e outras ações.

Não tem como falar em melhor gerenciamento de resíduos sem atentar à percepção e às práticas cotidianas da sociedade civil, visto que esse é um componente-chave para consolidação da Agenda. Também se torna importante estudar qual o entendimento e as práticas que são realizadas por profissionais que estão sendo formando na área ambiental sobre um assunto tão impactante que assola todo um planeta e seus recursos ambientais. Assim, este trabalho tem como objetivo investigar a percepção sobre a produção, consumo, destinação das sacolas plásticas e verificar quais ações vêm sendo desempenhadas por ingressantes do curso de Gestão Ambiental da Universidade do Estado do Rio Grande do Norte no tocante à produção e consumo de sacolas plásticas.

\section{REFERENCIAL TEÓRICO}

Com o avanço das tecnologias, novas substâncias são sintetizadas e novos produtos vão sendo inseridos na sociedade. A partir da primeira Revolução Industrial, houve uma mudança nos padrões de produção e de consumo, onde foram aparecendo novos insumos para fabricação de bens materiais. Alves e Araújo (2018) chamam atenção para a mudança da constituição de resíduos gerados pela sociedade, onde antes predominavam os resíduos orgânicos, que são de fácil decomposição, e depois com a inserção de novos insumos produtivos de composição mais complexa, detendo diferentes tipos de substâncias inorgânicas que exigem múltiplas destinações.

Uma classe de insumos que passou a ser produzido em grande escala foi a dos polímeros, que são moléculas complexas formadas da repetição de unidades químicas denominadas monômeros (SILVA; RABELO, 2017). Os polímeros sempre existiram naturalmente, um exemplo deles são as proteínas (que possuem como monômeros os aminoácidos), segundo Silva e Rabelo (2017), só em meados do século XVI os polímeros passaram a ser extraídos artificialmente, obtendo mais atenção e passando a serem comercializados.

O plástico é o principal subproduto dos polímeros, e possuem inúmeras aplicabilidades, pois apresentam uma série de características que proporcionam seus usos múltiplos, tais como: 
resistência à corrosão, flexibilidade, elasticidade, durabilidade, transparência e baixa condutividade (OZÓRIO et al, 2015). Devido a sua multiaplicabilidade o plástico foi intensamente disseminado em todos os setores produtivos, e hoje os produtos que não o contêm na sua composição, vêm embalados por ele. Isto é, o plástico é usado desde a indústria de eletrônicos até a de embalagens.

Outro vilão ambiental é a nafta, um subproduto obtido da destilação fracionada do petróleo utilizado como matéria-prima no plástico (SILVA; RABELO, 2017). O petróleo é um combustível fóssil não renovável, que de acordo com Martins et al (2018, p. 71) sua exploração acarreta uma série de potenciais impactos, tais como a grande geração de resíduos sólidos e oleosos de difícil descarte, emissão de gases entre outros. De acordo com Alves e Araújo (2018) estima-se que $4 \%$ da produção mundial de petróleo seja destinada à indústria do plástico, que resultam em cerca de 250 milhões de toneladas de resinas termoplásticas, de onde o Brasil colabora com 6,5 milhões de toneladas (Abiplast, 2014).

O consumo mundial de plástico tornou-se tão excessivo que tem desencadeado inúmeros problemas socioambientais, que vão desde a sua produção até sua destinação final. Boa parte do plástico descartado de maneira inadequada acaba chegando ate o oceano e por vezes esse material não precisa percorrer nenhum percurso, pois são despejados diretamente no oceano. O primeiro relato de resíduos plásticos nos oceanos foi em torno da década de 1960 (FREINKEL, 2011 apud MIZOGUCHI, 2019). De acordo com Jambeck et al. (2015 apud MIZOGUCHI, 2019) no ano de 2010, entre 4,8 a 12,7 milhões de toneladas de plástico gerado em terra firme foram descartadas nos oceanos. Esse dado é assustador, ainda mais se pensarmos que essa estatística se baseia nos plásticos contidos na superfície do oceano. Se pensarmos que ainda há muito plástico com densidade maior que a da água, ou seja, que fica submerso nos oceanos, esse dado pode ser bem maior.

Os resíduos que são despejados nos oceanos tendem a se concentrar em certas áreas por conta da movimentação da água, gerando o que é chamado de Grande Porção de Lixo do Pacífico (GPLP), zona com uma área de 1,6 milhões de $\mathrm{km}^{2}$ que contém em média 79 mil toneladas de plásticos (LIBRETON, 2018 apud MIZOGUCHI, 2019).

São inúmeros os impactos da disposição inadequado desse resíduo no ambiente, quando presente no oceano a fauna marinha confunde com alimento ou se enroscam e acabam morrendo. Segundo Mizoguchi (2019) mais de 250 espécies marinhas são ameaçadas pelos resíduos plásticos em seu habitat, com destaque às tartarugas, pinguins, baleias, peixes etc. A difusão do descarte dos resíduos sólidos ameaça toda a dinâmica do ecossistema marinho e suas interrelações com demais ecossistemas, o qual essa problemática se tornou meta até 2025 do Objetivo do Desenvolvimento Sustentável 14, denominado "Vida de baixo D'água" que busca prevenir e reduzir significativamente a poluição marinha de todos os tipos, especialmente a advinda de atividades terrestres.

Além disso, a saúde humana também é afetada pela disseminação de microplásticos nos oceanos, pois muitos desses voltam para nós através da água. Nos dados de COX et al. (2019 apud MIZOGUCHI, 2019) ingerimos de 81 a 123 mil pedaços de microplásticos por ano, e o consumo de água engarrafada pode aumentar 22 vezes essa quantidade.

Quando fala-se da problemática do consumo, nos remetemos ao produto plástico mais acessível a todos e que está presente direta e indiretamente em todas as compras realizadas: as sacolas plásticas. Conforme mostrado por Lozenzett (2013), 10\% de todos os resíduos gerados no Brasil corresponde às sacolas plásticas, onde um brasileiro consome cerca de 790 sacolas plásticas por ano. Dentre todos os resíduos plásticos, as sacolas contêm um dos maiores potenciais de impacto, pois 
facilmente entopem bueiros, ocasionam a morte de animais e pelo seu baixo peso podem ser levadas pelo vento, o que aumenta seu grau de dispersão. Na produção das sacolas, normalmente, usa-se de matéria-prima o Polietileno de Alta Densidade (PEAD) e o Polietileno de Baixa Densidade (PEBD), que são os polímeros mais fáceis de serem produzidos, pois possuem baixo custo de produção e suas fórmulas químicas são as mais simples da categoria dos polímeros (COUTINHO; MELLO; MARIA, 2003). Uma das principais vantagens no uso desses polímeros para confecção das sacolas plásticas é a resistência e durabilidade proporcionada a essas embalagens. Porém, há uma dualidade nessa característica: de acordo com Santos et al (2012) a durabilidade é um dos pontos negativos das sacolas plásticas quando elas são mal acondicionadas no ambiente, pois podem levar de 100 a 400 anos para se degradar. Os autores demonstram uma série de impactos causados pela má destinação das sacolas, como: entupimento de canais de drenagem e alagamento de vias públicas, poluição visual, influência na alimentação da vida selvagem, foco no crescimento de larvas de mosquitos transmissores de doenças, como dengue, entre outros.

Em alguns países há diversas iniciativas que incentivam a redução do uso dessas sacolas: em abril de 2019 a União Europeia aprovou uma diretiva que proíbe o uso de pratos, canudos, talheres e cotonetes e isso passará a valer em 2021 (CONTIOUTRA, 2019). No Brasil, essas ações se restringem apenas a alguns estados. Isso porque, de acordo com Alves e Araújo (2018), a problemática das sacolas plásticas tem ganhado visibilidade recentemente e no geral as ações para resolução do problema ainda se encontram incipientes.

Para Horst e Dalmoro (2012), o consumismo é o fator principal no aparecimento de danos socioambientais. Quando falamos das sacolas, não é diferente. Quanto a isso, inúmeras resoluções podem vir a ser postas em prática sobre a questão das sacolas plásticas: mudança na matéria-prima usada para produzi-las, sistemas eficientes de gerenciamento de resíduos plásticos e redução nos padrões de consumo e produção sustentável.

E se tratando de sustentabilidade um dos principais documentos que orientam as práticas de diversos países desde 2015 é a Agenda 2030, um documento elaborado no âmbito da Organização das Nações Unidas (ONU). O presente trabalho destaca o ODS 12, intitulado "Consumo e Produção Sustentáveis", e mais especificamente as metas 12.4, que visa até 2020 alcançar o manejo adequado dos produtos químicos e resíduos para minimizar seus impactos negativos sobre a saúde humana e o meio ambiente; 12.5, que pretende até 2030 reduzir substancialmente a geração de resíduos por meio da prevenção, redução, reciclagem e reuso; e a meta 12.7 , que objetiva promover práticas de compras públicas sustentáveis.

A resolução da problemática das sacolas plásticas, como o próprio ODS condensa, depende igualitariamente de mudanças na produção e consumo (além da reciclagem). Inicialmente é necessário buscar outras fontes de polímeros para produção de plásticos, como os polímeros naturais (celulose, amido entre outros). Mas não adianta ter sacolas produzidas de forma sustentável se consumo continuar da mesma maneira que as sacolas convencionais. Não demoraria muito para mesmo com essa mudança de produção a questão das sacolas ocasionariam problemas advindos de outros setores, como desmatamento de árvores para retirada da celulose.

Com isso, é importante saber como a temática das sacolas plásticas vem sendo vista nos setores da sociedade, principalmente, em potenciais interventores nos problemas socioambientais, como os discentes do curso de Gestão Ambiental. Nessa direção, o objetivo do presente trabalho foi identificar as concepções dos ingressantes do curso de Gestão Ambiental da Universidade do Estado 


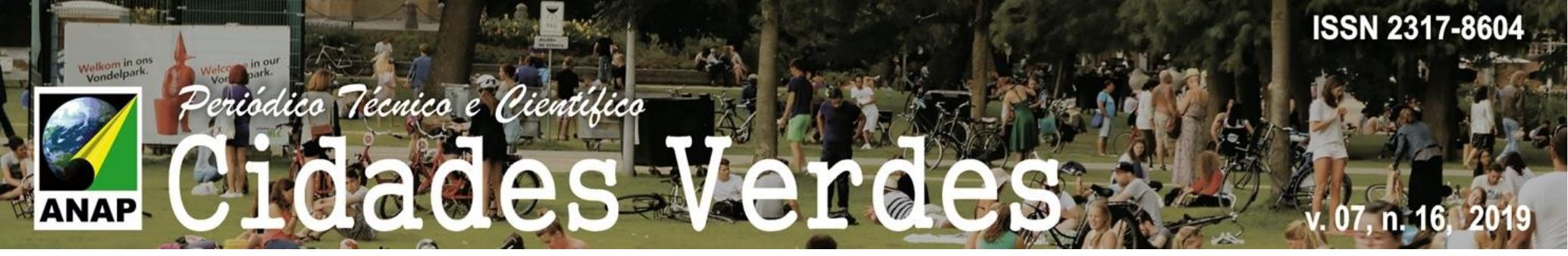

do Rio Grande do Norte (UERN), sobre a problemática da produção, consumo e destinação das sacolas plásticas. O trabalho foi guiado a partir de uma questão central: qual a percepção dos ingressantes do curso de Gestão Ambiental da UERN sobre a problemática da produção, consumo e destinação dos plásticos e frente a isso, quais suas práticas?

\section{METODOLOGIA}

A pesquisa foi desenvolvida com 16 discentes do primeiro período do bacharelado em Gestão Ambiental da UERN, campus Central, localizado na Rua Professor Antonio Campos s/n, Presidente Costa e Silva, município de Mossoró (RN).

O trabalho se baseia, em um primeiro momento, em pesquisa bibliográfica, que de acordo com Fonseca (2002) se concretiza na leitura de trabalhos desenvolvidos, anteriormente, sobre a temática, a fim de estabelecer um panorama da problemática discutida no estado atual. Adotou-se a abordagem quantitativa, que para Diehl (2004), se caracteriza pelo uso da quantificação, coleta e tratamento das informações obtidas por meio de técnicas estatísticas.

No segundo momento foi realizada uma pesquisa de campo com a finalidade de aplicar questionários semiestruturados com perguntas abertas e fechadas a estudantes ingressantes do curso de Gestão Ambiental da UERN. O questionário continha 16 questões que foram divididas em três categorias: a primeira focava na produção dos plásticos, a segunda seção investigava o consumo e a destinação das sacolas dadas pelos participantes da pesquisa e a última seção sobre a resolução da problemática das sacolas plásticas.

Os dados obtidos a partir da aplicação dos questionários foram tabulados e convertidos em gráficos com uso do software Excel 2013.

\section{RESULTADOS}

Verificou que em relação ao perfil dos entrevistados, $50 \%$ eram do gênero feminino e $50 \%$ do gênero masculino, e $56,25 \%$ apresentava idade entre 18 e 22 anos, 37,5\% idade entre 22 e 30 anos e 6,25\% mais de 30 anos. Desse total, $81,25 \%$ afirmaram ser o curso de Gestão ambiental o primeiro curso superior que ingressaram, 12,5\% ingressaram anteriormente em outros mas não finalizaram e 6,25\% finalizou um curso anterior, de licenciatura em Geografia. A primeira questão (Figura 1), da categoria de produção dos plásticos, questionava sobre a principal matéria-prima usada na produção dos plásticos. 


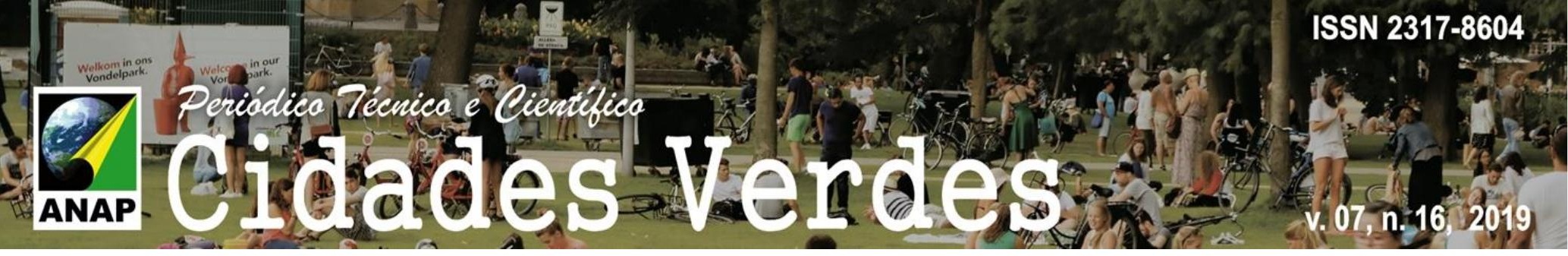

Figura 1: Matéria-prima do plástico

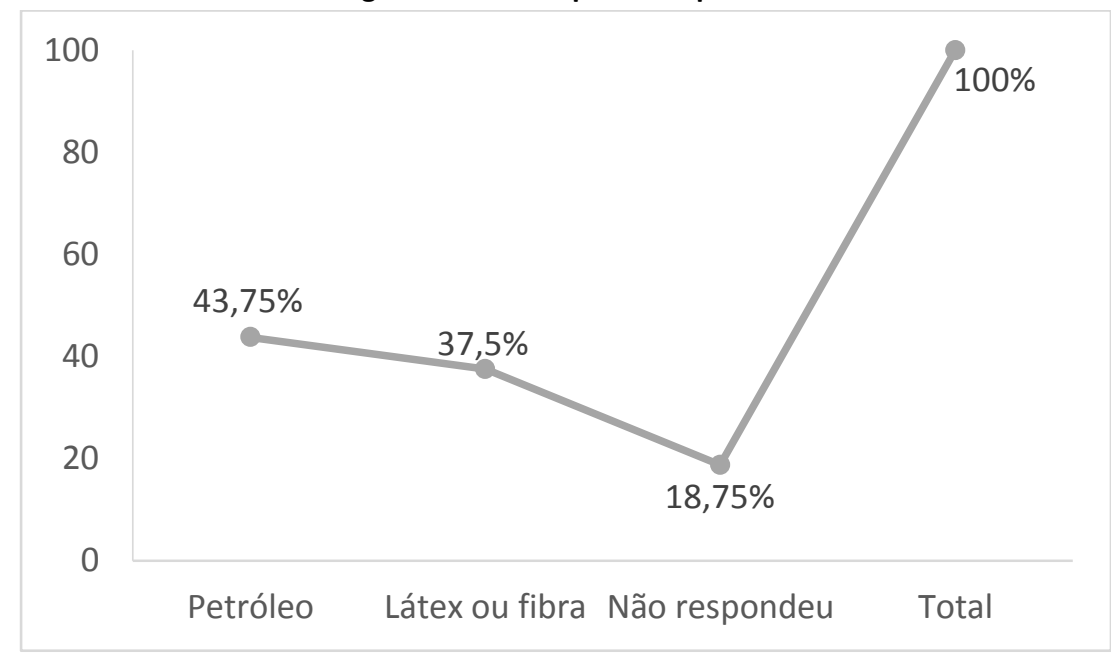

Fonte: pesquisa de campo, 2019

Menos da metade dos entrevistados $(43,75 \%)$ indicaram o petróleo como matéria-prima do plástico. $37,5 \%$ responderam que o insumo utilizado na produção dos plásticos são os látex e fibras. Resende (2018) divide os polímeros em três principais categorias: a dos plásticos, a das borrachas e das fibras. Portanto, pode-se considerar que pouco mais da metade $(56,25 \%)$ não sabem definir qual a principal matéria-prima do plástico.

Outra pergunta foi sobre os diferentes tipos de plásticos, que são divididos em seis principais classes (Figura 2) de acordo com a NBR 13.230/2008 (citado por ECYCLE). Todos os produtos de plástico carregam o símbolo correspondente ao tipo de plástico que o compõe, o que vai facilitar posteriormente na definição de como tal produto será reciclado.

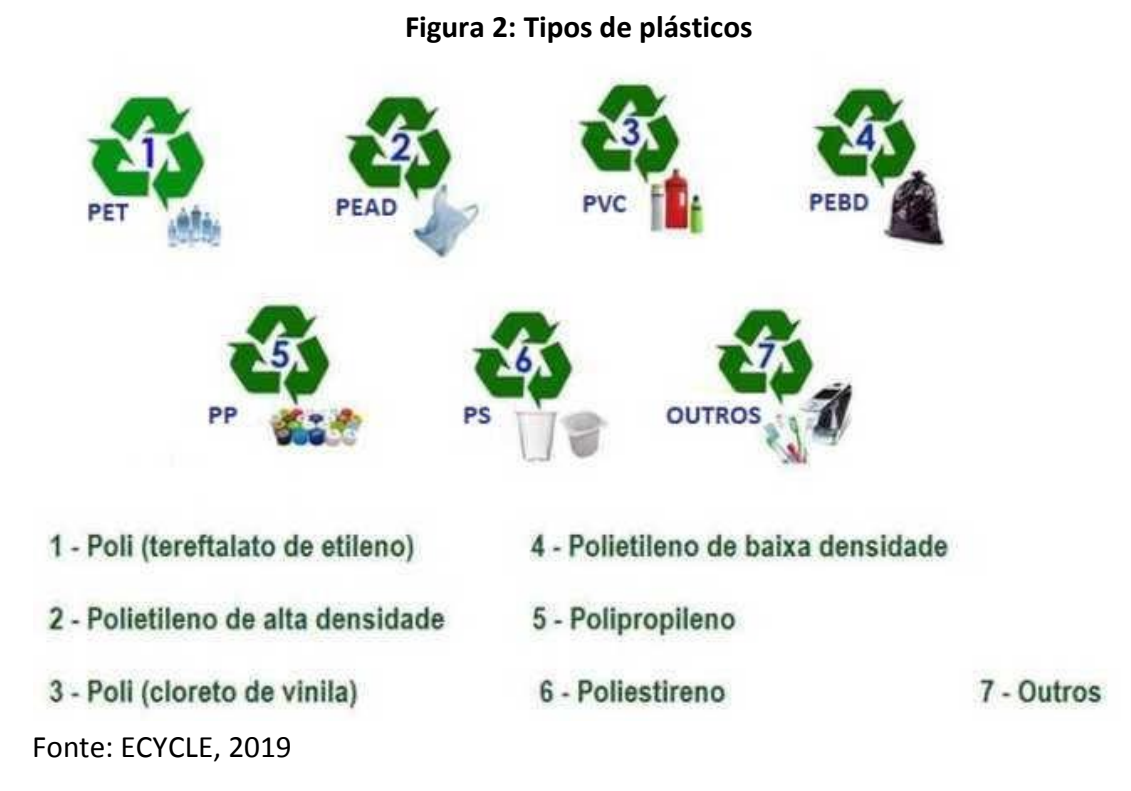

Observou-se que $81,25 \%$ dos discentes afirmaram não saber o que significa essa numeração carregada nas embalagens de plásticos e apenas 18,75\% marcaram que sim (Figura 3). 


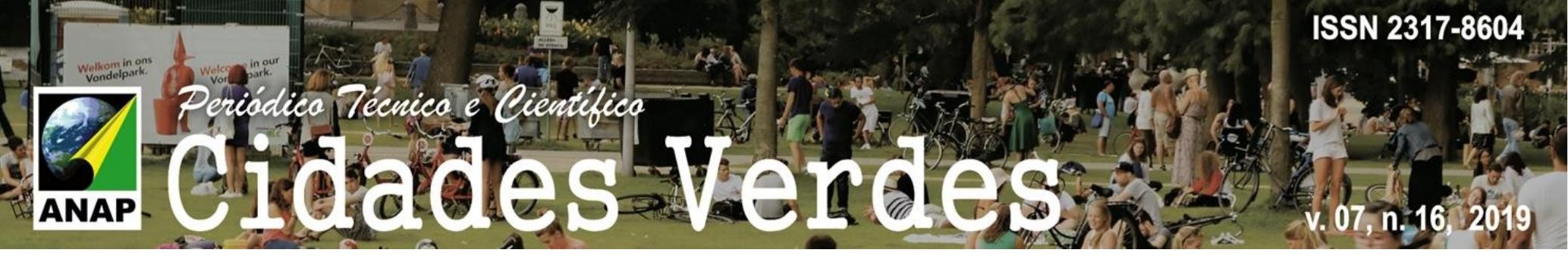

Figura 3: Numeração dos rótulos de plásticos

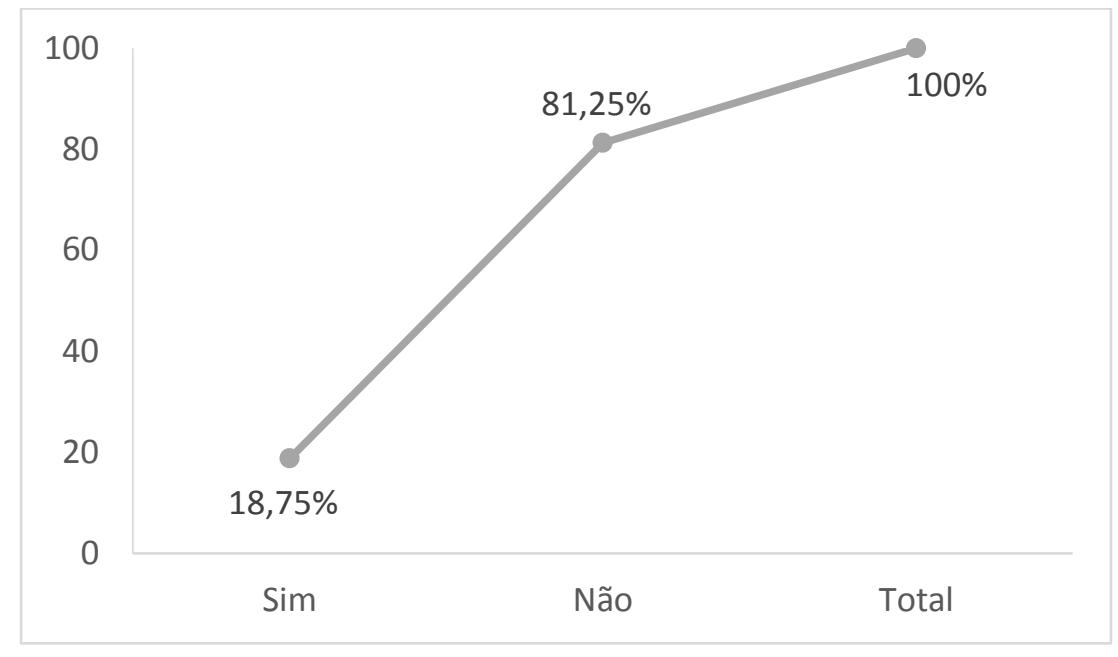

Fonte: pesquisa de campo, 2019

Foi ainda questionado sobre os impactos ambientais causados a partir da destinação inadequada das sacolas plásticas. É interessante notar que os participantes que responderam $(68,75 \%)$ conseguiram citar apenas um, enquanto o restante (31,25\%) não conseguiu citar nenhum (Figura 4). $50 \%$ das pessoas citara ou o impacto do alagamento causado pelo entupimento dos canais de drenagem ou impactos relacionados à poluição do ar, água e solo.

Figura 4: Impactos causados pela má destinação das sacolas plásticas

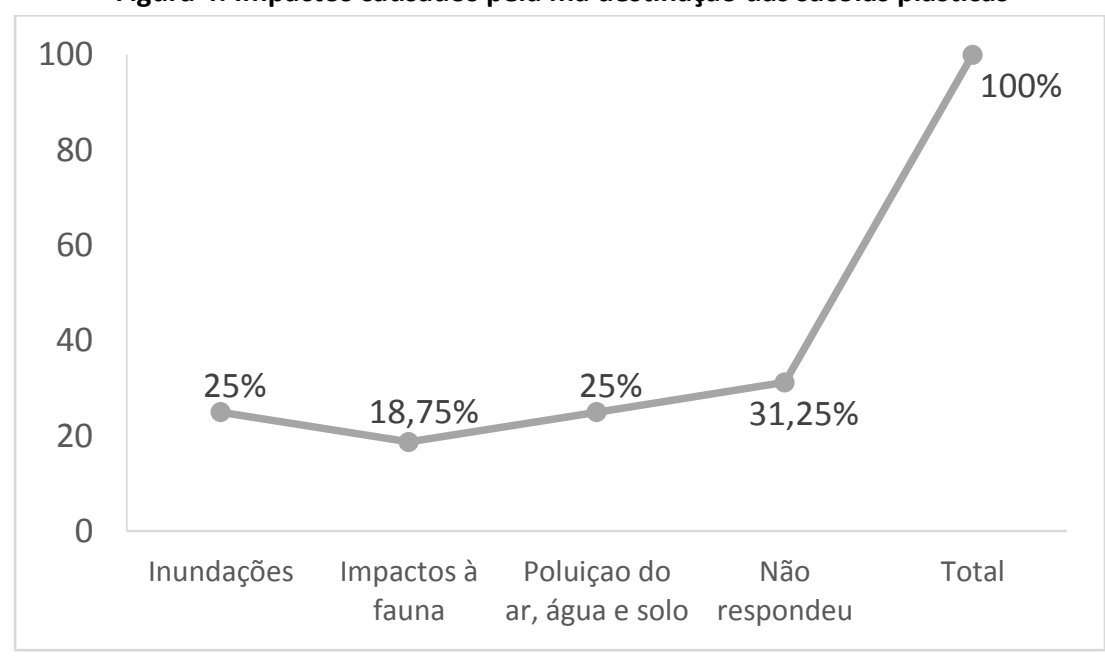

Fonte: pesquisa de campo, 2019

No estudo realizado por Lima e Avelino-Capistrano (2015) é ressaltado que muitas pessoas sabem indicar o impacto final da poluição por plásticos, mas não sabem identificar a forma como isso acontece. $O$ processo da degradação dos polímeros depende das condições ambientais que eles são submetidos. Normalmente, como mostrado por Silva e Rabelo (2017), os plásticos são degradados pela ação da luz solar, do calor, da tensão mecânica e, quando nos oceanos, pela ação da água. De acordo com esses autores, a degradação dos polímeros ocorre pela mudança da estrutura química desses materiais, que origina petropolímeros, substâncias extremamente poluentes. Ao focar nas 


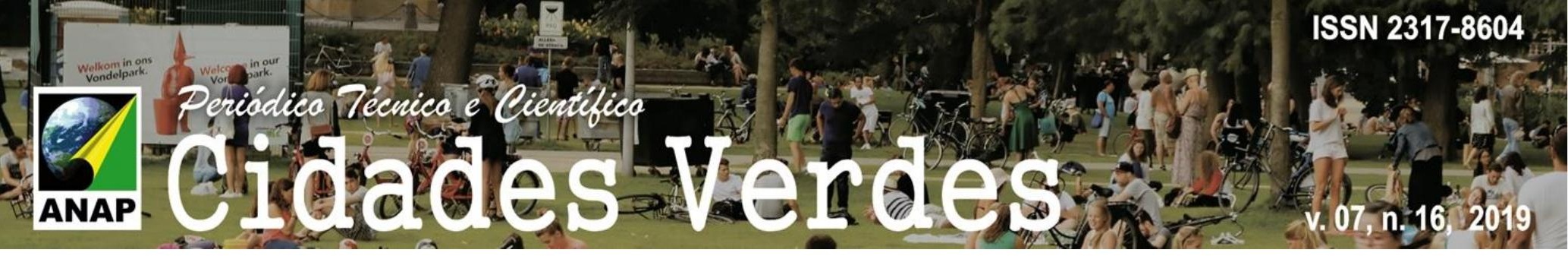

questões acerca do consumo das sacolas, a Figura 5 mostra a frequência semanal que os participantes vão ao supermercado. $43,75 \%$ das pessoas afirmaram que vão às compras de 3 a 5 vezes por semana.

Figura 5: Frequência de ida aos supermercados

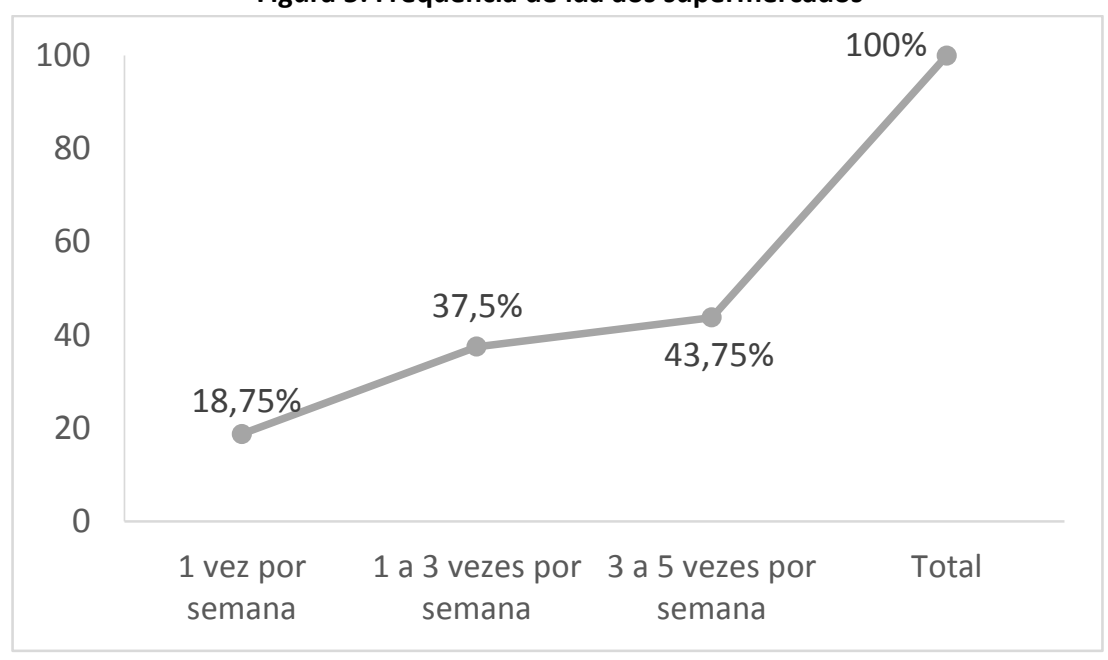

Fonte: pesquisa de campo, 2019

Ao considerar o mínimo contido na alternativa ( 3 vezes semanais) e que a cada ida uma pessoa consuma pelo menos duas sacolas plásticas, no final de um ano (48 semanas), ela terá consumido no mínimo 288 sacolas plásticas. Essa estatística é otimista se comparada à de Lorenzett et al (2013), que indica que cada brasileiro consome uma média de 790 sacolas por ano. Já nos dados de Alves e Araújo (2018) esse consumo se traduz num peso per capita de $19 \mathrm{~kg}$ de sacolas por ano.

Quanto às alternativas oferecidas pelos supermercados para redução do consumo das sacolas plásticas, a maioria dos participantes afirmou que os supermercados visitados não oferecem nenhuma alternativa de transporte de mercadoria além das sacolas plásticas. Além do supermercado não oferecer alternativas, $93,75 \%$ das pessoas não procuram usar sacolas retornáveis, ecobags ou alguma outra alternativa (Figura 6).

Figura 6: Uso de sacolas retornáveis pelos participantes

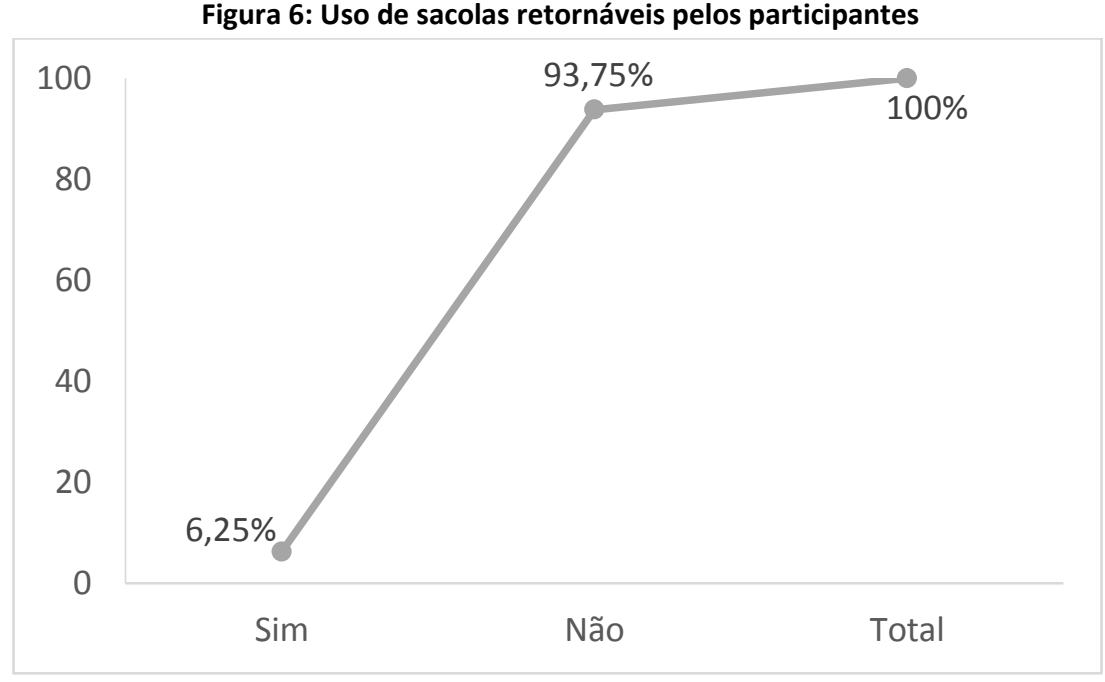

Fonte: pesquisa de campo, 2019 


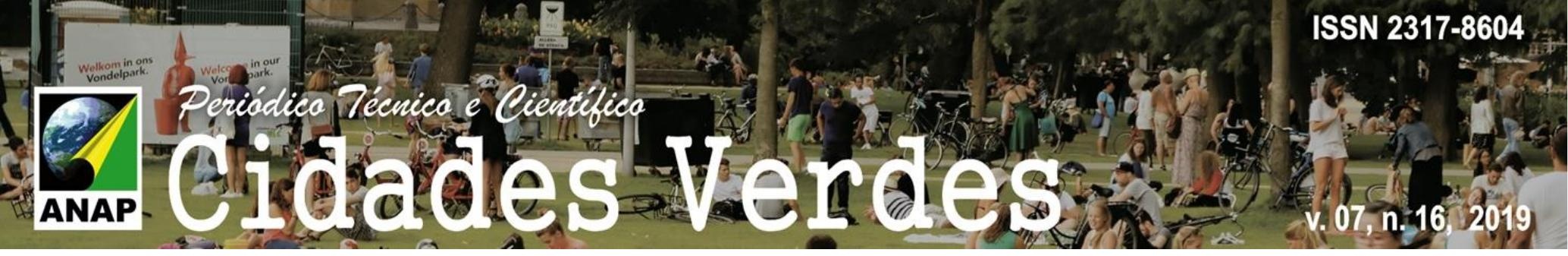

Horst e Dalmoro (2012) alertam que consumidores entendem que suas ações causam impactos socioambientais negativos, mas poucos estão dispostos a mudá-las. O mesmo acontece no caso do uso das sacolas, onde muitos percebem o impacto causado pelo consumo e pelo descarte indevido dessas, mas poucos estão dispostos a recorrer a outros meios de transportar seus produtos. $\mathrm{Na}$ pesquisa realizada por Lima e Avelino-Capistrano (2015) foi relatado que apenas 6,5\% das pessoas entrevistadas utilizam ecobags nas compras.

Algumas alternativas de substituição indicadas por Santos et al. (2012) são: uso de sacolas reutilizáveis, sacolas biodegradáveis, sacolas oxibiodegradáveis, de papel e de plástico reciclado. Especificamente, no caso das sacolas plásticas, ações voltadas para redução do consumo, associada à melhor qualidade das sacolas para assegurar sua reutilização para outros fins permitiriam atender aos itens redução e reutilização (SANTOS el al., 2012). Além disso, há supermercados que cobram pelo uso de sacolas convencionais como forma de diminuir seu consumo.

Quando questionados se pagariam por sacolas plásticas, $87,5 \%$ dos participantes afirmaram que não pagariam (Figura 7). Essa é uma ação apontada pela maioria dos entrevistados por Alves e Araújo (2018) como sendo uma das mais efetivas para reduzir o consumo de sacolas plásticas, uma vez que a sociedade tende a ser mais sensível a questões econômicas.

Figura 7: Possibilidade de compra por sacolas convencionais

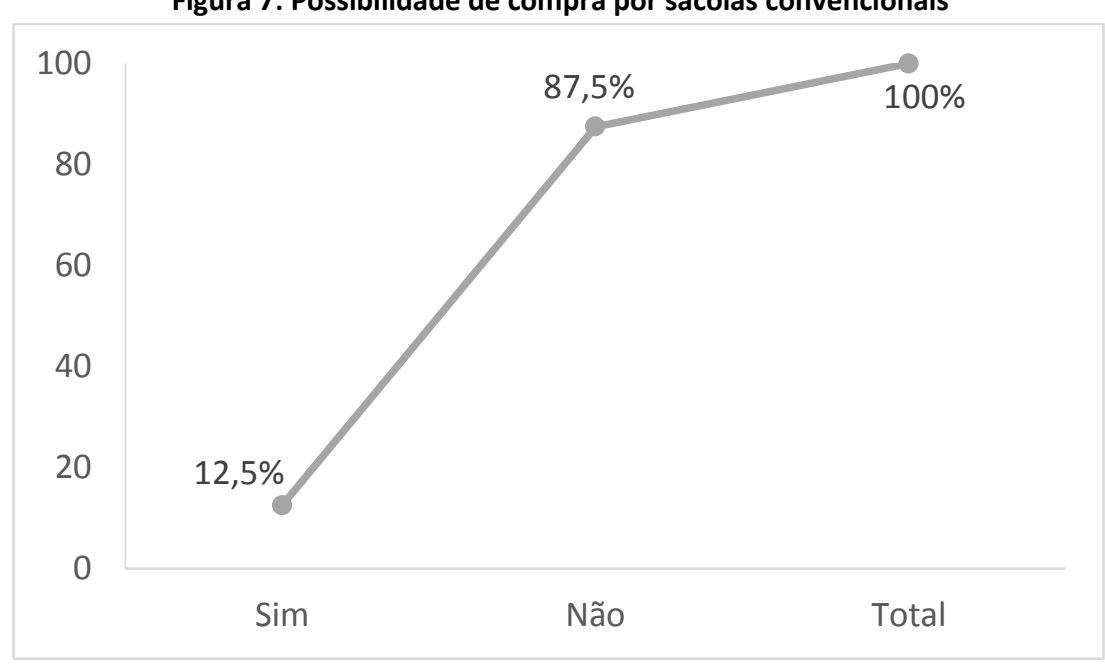

Fonte: pesquisa de campo, 2019

A categoria de perguntas sobre a resolução do problema das sacolas plásticas iniciou-se questionando sobre qual a melhor prática a ser adotada pelos supermercados para a redução do consumo das sacolas (Figura 8). 


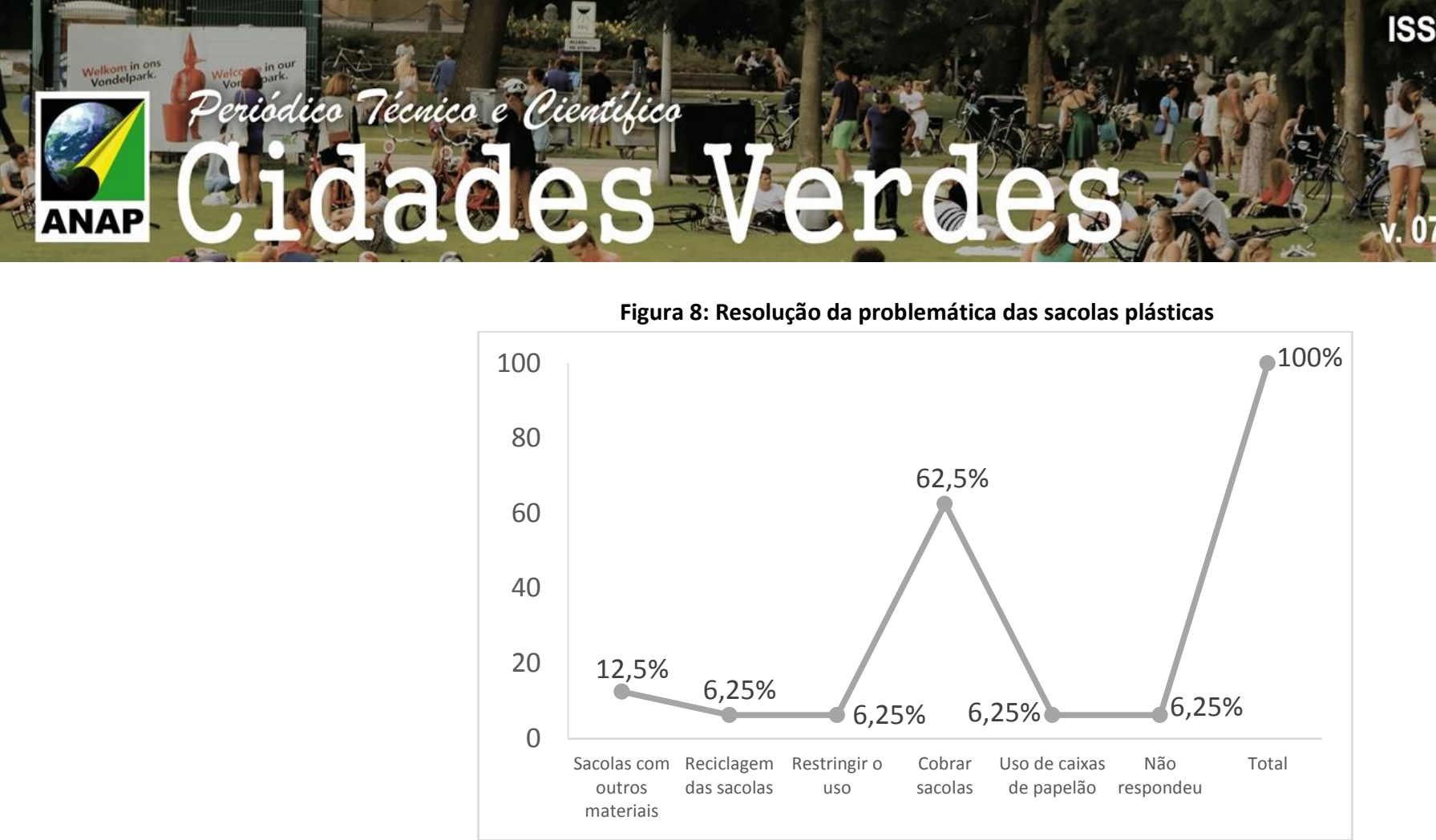

Fonte: pesquisa de campo, 2019

Observa-se que $62,5 \%$ respondeu que a melhor alternativa é a cobrança das sacolas, $12,5 \%$ falou que o problema seria resolvido a partir da disponibilização de sacolas feitas com outros insumos, $6,25 \%$ indicou a reciclagem das sacolas, $6,25 \%$ a restrição do uso enquanto $6,25 \%$ considera a reciclagem das sacolas usadas como principal resposta.

\section{CONCLUSÃO}

O consumo de plástico aumentou aceleradamente nos últimos anos, o que tem acarretado impactos socioambientais visíveis tanto advindos da sua produção, pois sua matéria-prima é obtida a partir de combustíveis fósseis, até seu destino final, pois a maioria do plástico acaba nos oceanos. Isso tem causado impactos ambientais, como a morte de animais aquáticos, poluição do solo, ar água e complicações à saúde humana.

A sacola é um dos produtos advindos do plástico que mais se destaca no quesito de consumo e destinação inadequada. Com isso, há necessidade da mudança tanto no modelo de produção das sacolas quanto do consumo, o que nos remete diretamente ao Objetivo de desenvolvimento Sustentável número 12, que aborda sobre Consumo e Produção Sustentáveis.

No que tange às pessoas que participaram da pesquisa desenvolvida, nota-se que elas são cientes dos impactos do uso e consumo dos plásticos, definindo como principais a poluição das águas, ar e solo. Porém, o quantitativo de estudantes que continuam utilizando as sacolas convencionais e não optando por outras alternativas é quase a totalidade de entrevistados. Além disso, as resoluções apontadas por eles para resolução dessa problemática são fragmentadas, pois é algo que não se resolveria apenas com uma mudança na produção, no consumo ou no gerenciamento de resíduos, mas que necessariamente perpassa por esses três conjuntos de fatores.

Torna-se importante, portanto, alertar sobre os danos causados pelo consumo de materiais plásticos, especialmente das sacolas, visto que essa prática já se tornou algo cultural. O papel dos gestores ambientais torna-se indispensável, pois é uma área que se insere diretamente em todas as etapas do problema aqui apresentado. É interessante, também, a realização de estudos desse tipo com egressos do curso, que hipoteticamente são dotados de outras visões e praticantes de outras ações a fim de estabelecer uma comparação entre ambas às situações. 
